\title{
Racial and Ethnic Disparities in Household Contact with Individuals at Higher Risk of Exposure to COVID-19
}

\author{
Abbreviations \\ COVID-19 \\ US \\ AAPI
}

Coronavirus disease 2019

United States

Asian American and Pacific Islander

J Gen Intern Med 36(5):1470-2

DOI: $10.1007 / \mathrm{s} 11606-021-06656-1$

(C) Society of General Internal Medicine 2021

\section{INTRODUCTION}

Household contact is a significant channel of transmission of SARS-CoV-2, the virus that causes coronavirus disease 2019 (COVID-19). ${ }^{1}$ Transmission of the virus can occur within the household after infection in the workplace. ${ }^{2}$ Moreover, racial disparities have been identified as a risk for occupational exposure to COVID-19. ${ }^{3}$ Identifying those at higher risk of contracting COVID-19 through household and occupational exposure is important for public health awareness and policy, as well as for understanding racial and ethnic disparities in infection rates and outcomes. ${ }^{4}$ We sought to identify racial/ ethnic categories associated with living in a household with someone who continues to work a job with higher risk of COVID-19 infection.

\section{METHODS}

Using nationally representative data from February through May 2020 from the Current Population Survey, we derived variables for self-reported occupation, sex, race and ethnicity; level of educational attainment; family income; whether the household is located in a metropolitan area; the number of household members in the labor force at the start of the period; and the range of household members' ages (Table 1). ${ }^{5}$ Our sample is composed of 66,384 individuals across 33,612 households surveyed in February and at least one other month in the period. Using publicly available data from the Occupational Information Network, we classified jobs as being at higher risk of COVID-19 if they require "moderately close" physical proximity to other people and cannot be done remotely. ${ }^{6}$

Fatima Rodriguez and David Scheinker served as senior and corresponding authors.

Received September 7, 2020

Accepted February 8, 2021

Published online March 5, 2021

\section{0}

We fitted multivariate logistic regression models with robust standard errors to estimate the odds ratio (OR) and 95\% confidence interval (CI) of living in a household with someone who worked for more than 1 month at a job at higher risk of COVID-19 infection during the period. Estimates were obtained separately for individuals indefined age groups (15-44 years old, 45-64 years old, and 65-85 years old) to account for interactions between age group and other covariates. All analyses were performed using the $\mathrm{R}$ programming language (version 4.0.2) and the estimatr and srvyr packages. Personlevel weights were provided by IPUMS. ${ }^{4}$

\section{RESULTS}

In unadjusted analyses, the baseline proportions of nonHispanic Whites living in a household with someone who worked more than 1 month at a job at higher risk of COVID-19 infection were $32.1 \%$ (CI, $31.3 \%$ to $32.9 \%$ ), $25.4 \%$ (CI, $24.6 \%$ to $26.2 \%$ ), and $8.7 \%$ (CI, $8.1 \%$ to $9.2 \%$ ) for age groups 15-44, 45-64, and 65-85, respectively (Figure 1).

In unadjusted comparisons to non-Hispanic Whites, individuals identifying as AAPI had an OR of 1.4 (CI, 1.2 to 1.6) and 2.8 (CI, 2.2 to 3.5) of living in such a household, for ages 45-64 and 65-85, respectively. Those identifying as Black had an OR of 1.2 (CI, 1.1 to 1.3), 1.2 (CI, 1.1 to 1.3), and 1.6 (CI, 1.3 to 1.9 ), for ages $15-44,45-64$, and 65-85, respectively. Those identifying as Hispanic had an OR of 1.2 (CI, 1.1 to 1.3 ), 1.7 (CI, 1.5 to 1.8 ), and 1.9 (CI, 1.5 to 2.3 ), for ages 15-44, 45-64, and 65-85, respectively. Finally, those identifying as two or more races ages $15-44$ had an OR of 1.3 (CI, 1.1 to 1.6$)$.

In adjusted comparisons to non-Hispanic Whites, individuals identifying as Black had an OR of 1.3 (CI, 1.2 to 1.4) and 1.3 (CI, 1.1 to 1.4) of living in such a household, for ages 1544 and 45-64, respectively. Individuals identifying as Hispanic ages 45-64 had an OR of 1.2 (CI, 1.0 to 1.3), and individuals identifying as two or more races ages $15-44$ had an OR of 1.2 (CI, 1.0 to 1.5$)$.

\section{DISCUSSION}

The primary limitations of this study are a lack of data on the job-specific risk of COVID-19 infection and actual virus transmission between household members. 
Table 1 Socioeconomic and Demographic Characteristics of Members of the Racial and Ethnic Groups Studied

\begin{tabular}{|c|c|c|c|c|c|c|c|}
\hline & $\begin{array}{l}\text { All } \\
(n=66,384)\end{array}$ & $\begin{array}{l}\text { White } \\
(n=45,823)\end{array}$ & $\begin{array}{l}\text { AAPI } \\
(n=3891)\end{array}$ & $\begin{array}{l}\text { Black } \\
(n=6306)\end{array}$ & $\begin{array}{l}\text { Hispanic } \\
(n=8804)\end{array}$ & $\begin{array}{l}\text { Mixed } \\
(n=932)\end{array}$ & $\begin{array}{l}\text { American } \\
\text { Indian, } \\
\text { Aleut, or } \\
\text { Eskimo } \\
(n=628)\end{array}$ \\
\hline Mean age $(95 \% \mathrm{CI})$ & $\begin{array}{l}46.7 \\
(46.5,46.9)\end{array}$ & $\begin{array}{l}49.3 \\
(49.1,49.5)\end{array}$ & $\begin{array}{l}44 \\
(43.4,44.6)\end{array}$ & $\begin{array}{l}44.3 \\
(43.8,44.9)\end{array}$ & $\begin{array}{l}40.6 \\
(40.2,41)\end{array}$ & $\begin{array}{l}36.1 \\
(34.8,37.4)\end{array}$ & $\begin{array}{l}43.8 \\
(41.9,45.7)\end{array}$ \\
\hline \multicolumn{8}{|l|}{ Age group } \\
\hline $15-44(\%)$ & 47.4 & 41.5 & 54.2 & 52.0 & 61.4 & 71.1 & 54.1 \\
\hline $45-64(\%)$ & 31.5 & 32.9 & 30.3 & 31.6 & 27.7 & 18.8 & 30.1 \\
\hline $65+(\%)$ & 21.1 & 25.6 & 15.5 & 16.4 & 10.9 & 10.0 & 15.8 \\
\hline $\begin{array}{l}\text { Probability of living in household } \\
\text { with someone working a higher-risk } \\
\text { job }(\%)\end{array}$ & 26.8 & 23.9 & 29.2 & 29.6 & 34.1 & 33.3 & 26.8 \\
\hline Male $(\%)$ & 48.4 & 48.7 & 46.7 & 45.7 & 49.8 & 48.7 & 49.1 \\
\hline \multicolumn{8}{|l|}{ Household income } \\
\hline$\$ 0-\$ 50,000(\%)$ & 36.2 & 32.0 & 25.5 & 50.7 & 46.0 & 34.1 & 50.1 \\
\hline$\$ 50,000-\$ 100,000(\%)$ & 31.7 & 32.1 & 29.0 & 29.5 & 32.3 & 31.3 & 36.4 \\
\hline$\$ 100,000-\$ 150,000(\%)$ & 15.6 & 17.3 & 18.2 & 10.7 & 11.6 & 18.6 & 7.6 \\
\hline$\$ 150,000+(\%)$ & 16.5 & 18.6 & 27.4 & 9.0 & 10.1 & 16.0 & 5.9 \\
\hline Mean number of household & 1.5 & 1.4 & 1.8 & 1.4 & 1.9 & 1.8 & 1.5 \\
\hline members in labor force $^{\dagger}(95 \% \mathrm{CI})$ & $(1.5,1.6)$ & $(1.4,1.5)$ & $(1.8,1.8)$ & $(1.4,1.4)$ & $(1.9,1.9)$ & $(1.8,0.1)$ & $(1.4,1.7)$ \\
\hline Mean household age range $(95 \% \mathrm{CI})$ & $\begin{array}{l}22.5 \\
(22.4,22.7)\end{array}$ & $\begin{array}{l}19.6 \\
(19.4,19.8)\end{array}$ & $\begin{array}{l}28.8 \\
(28.1,29.5)\end{array}$ & $\begin{array}{l}24.5 \\
(24,25.1)\end{array}$ & $\begin{array}{l}29.3 \\
(28.9,29.7)\end{array}$ & $\begin{array}{l}23.8 \\
(0.4,0.4)\end{array}$ & $\begin{array}{l}27.2 \\
(25.2,29.2)\end{array}$ \\
\hline Household in metropolitan area $(\%)$ & 12.7 & 16.5 & 1.9 & 8.5 & 4.4 & 9.4 & 31.6 \\
\hline \multicolumn{8}{|l|}{ Educational attainment } \\
\hline High school or less (\%) & 40.4 & 35.4 & 27.9 & 46.4 & 59.1 & 41.2 & 50.9 \\
\hline College or more $(\%)$ & 59.6 & 64.6 & 72.1 & 53.6 & 40.9 & 58.8 & 49.1 \\
\hline
\end{tabular}

All statistics computed using person-level sample weights

AAPI, Asian American and Pacific Islander

${ }^{+}$At the start of the period of interest

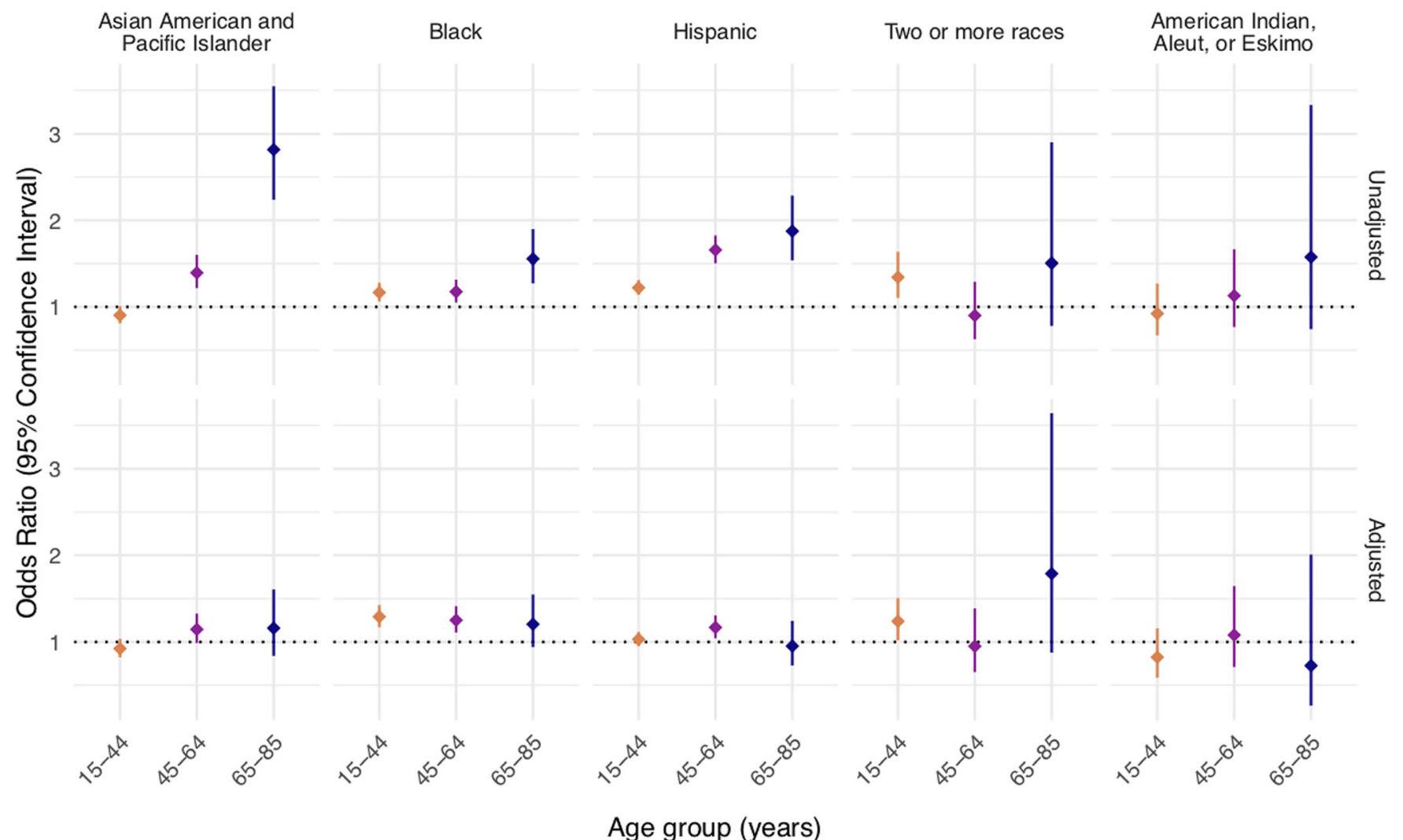

Figure 1 Racial and ethnic differences in the probability of living in a household with someone continuing to work at a job at higher risk for contracting COVID-19. Top: Unadjusted multivariate logistic regression. The dependent variable indicates the OR of living in a household with someone continuing to work at a job at higher risk of COVID-19 infection. Bottom: Multivariate logistic regression adjusted for sex, level of education attainment, family income, whether the household is located in a metropolitan area, the number of household members in the labor force at the start of the period of interest, and the range of ages of household members. 
Using nationally representative data, we identified racial/ ethnic groups significantly more likely to live with someone continuing to work at a job at higher risk of COVID-19 infection, in unadjusted and adjusted analyses. These findings build upon earlier work on racial and ethnic disparities in COVID-19-related outcomes by demonstrating the combined impact of racial disparities in both occupational and household exposure risk, and shed light on potential contributors. ${ }^{3}$ In particular, our findings suggest that racial and ethnic disparities in exposure to SARS-CoV-2 may be drivenby household exposure to someone working a job at higher risk of COVID19 infection.

Role of the Funder/Sponsor: The work was not supported by external funding.

Sandra T. Kong, $\mathrm{MS}^{1}$

Raymond Y. Lee, $B A^{2,3}$

Fatima Rodriguez, $M D, M P H^{4}$

David Scheinker, $P h D^{2,3,5}$

${ }^{1}$ Department of Biomedical Data Science, Stanford University School of Medicine,

Stanford, CA, USA

${ }^{2}$ Clinical Excellence Research Center, Stanford University School of Medicine,

Stanford, CA, USA

${ }^{3}$ Department of Management Science and Engineering, Stanford University School of Engineering,

Stanford, CA, USA

${ }^{4}$ Division of Cardiovascular Medicine and the Cardiovascular Institute, Stanford University School of Medicine,

Stanford, CA, USA

${ }^{5}$ Division of Pediatric Endocrinology, Stanford University School of Medicine,

Stanford, CA, USA

Corresponding Author: David Scheinker, $\mathrm{PhD}$; Department of Management Science and Engineering, Stanford University School of Engineering, Stanford, CA, USA (e-mail: dscheink@stanford.edu).
Authors' Contribution Mr. Scheinker, Mr. Lee, and Ms. Kong had full access to all of the data in the study and take responsibility for the integrity of the data and the accuracy of the data analysis. Concept and design: Scheinker, Lee, and Kong.

Acquisition, analysis, or interpretation of data: Scheinker, Lee, and Kong.

Drafting of the manuscript: Scheinker, Rodriguez, Lee, and Kong. Critical revision of the manuscript for important intellectual content: Scheinker and Rodriguez.

Statistical analysis: Scheinker, Lee, and Kong.

Administrative, technical, or material support: Scheinker, Rodriguez, Lee, and Kong.

Supervision: Scheinker and Rodriguez.

Funding Dr. Rodriguez is funded by a career development award from the National Heart, Lung, and Blood Institute (KO1 HL 14460) and the American Heart Association/Robert Wood Johnson Harold Amos Medical Faculty Development Program.

\section{Declarations:}

Conflict of Interest: Drs Rodriguez and Scheinker reported having an advisory role with Carta Healthcare. Dr. Rodriguez has served as an advisor to HealthPals, NovoNordisk, Janssen, and Novartis.

\section{REFERENCES}

1. Luo $\mathbf{L}$, Liu $\mathbf{D}$, Liao $\mathbf{X}$, et al. Contact settings and risk for transmission in 3410 close contacts of patients with COVID-19 in Guangzhou, China. Ann Intern Med. 2020. https://doi.org/10.7326/m20-2671.

2. Pung R, Chiew CJ, Young BE, et al. Investigation of three clusters of COVID-19 in Singapore: implications for surveillance and response measures. Lancet. 2020;395(10229): 1039-1046. https://doi.org/10. 1016/s0140-6736(20)30528-6.

3. Hawkins D. Differential occupational risk for COVID-19 and other infection exposure according to race and ethnicity. Am J Ind Med. 2020. https://doi.org/10.1002/ajim.23145.

4. Gross C, Essien U, Pasha S, et al. Racial and ethnic disparities in population-level Covid-19 mortality. J Gen Intern Med. 2020. https://doi. org/10.1007/s11606-020-06081-w.

5. Flood S, King $\mathbf{M}$, Rodgers $\mathbf{R}$, et al. Integrated Public Use Microdata Series, Current Population Survey: Version 7.0 [dataset]. Minneapolis: IPUMS, 2020. https://doi.org/10.18128/D030.v7.0.

6. Dingel J, Neiman B. How many jobs can be done at home? Becker Friedman Inst. 2020. https://doi.org/10.3386/w26948.

Publisher's Note Springer Nature remains neutral with regard to jurisdictional claims in published maps and institutional affiliations. 